\title{
On-Call Radiology
}

Like nearly all of you, I cover after-hours procedures in interventional radiology (IR). No matter how you look at it, basically, at this stage of my career, not much in IR interests me at $3 \mathrm{AM}$. Some people like the excitement of late-night cases; I think those people need head CTs. But, as interventional radiologists assume larger and larger roles in patient management, we are more commonly needed after-hours. It is a price of being successful. I hate doing unnecessary procedures afterhours. At night, an academic hospital can be a dangerous place. Often, the support system is both unresponsive and inexperienced. Two things are difficult about after-hours IR cases. First, as the on-call interventional radiologist, you need to determine whether an intervention is indicated and urgent. And if so, you then have to go do it. Sometimes the former is more painful than the latter.

In my hospital, when things go wrong during an after-hours procedure in IR, there is often no safety net. Residents who run the hospital at night are commonly trying to prove themselves by being independent and demonstrating competence-sometimes these qualities seem mutually exclusive. Clinical residents act as though they need to fight for procedures because of the perception that on-call services don't want to be bothered at night. It is difficult at times to have a reasonable discussion because people are tired and short-tempered. Any pointed questions are taken as an affront to competence (or lack thereof). In fact, on many occasions, efforts are well intentioned but misdirected. Occasionally, these interchanges are amusing. At one time or another, I've been asked to insert an IVC filter in a patient with portal vein thrombus, insert transjugular portosystemic shunts in someone with arterial bleeding, and perform uterine artery embolization in the $\mathrm{OR}$ without fluoroscopy.

This past weekend, I awoke at 3 AM (it always seems to be at $3 \mathrm{AM}$ for me) to the sound of my beeper. I'm unclear on the reason-fight or flight, interruption of a nice dream, or whatever-but I'm neither coherent nor pleasant when this happens. I typically go through
Elisabeth Kübler-Ross's five stages of grief in $\sim 30$ seconds:

- Denial: This can't be happening. You have got to be kidding me. I'm being paged at 3 AM?

- Anger: Why did I take this call? What was I thinking in 1996 by doing an IR fellowship?

- Bargaining: Maybe it can wait until morning.

- Depression: This sucks. I should have done mammography.

- Acceptance: Another call, another bleeder...

I was a bit surprised to see it was the resident oncall paging me rather than one of our fellows who was also on-call with me. We train our residents to recognize clinical scenarios, evaluate studies and patients, and facilitate appropriate requests. They are also instructed to resist unnecessary and unwarranted therapy. Equivocal issues are discussed with the fellow on-call and then with attending physicians as necessary. At least, that is the way it should go.

As usual, it took me a few attempts to dial the 10digit number correctly (that should give you some indication of my technical ability at this hour).

Resident: Dr. Funaki, I'm sorry to bother you, but the fellow hasn't responded to my pages.

Me: OK, she's fired.

Resident: What? Oh, uh, urology has a 22-year-old man who was transferred from another hospital with a perirenal collection that they want drained.

Me: At 3 AM?! Is he septic, hypotensive . . . who wants this done?

Resident: The patient is rock-solid stable, but the collection is compressing the kidney on CT and there is a delay in excretion on the affected side. The attending wants it done for medicolegal reasons.

Me: What?

Resident: Maybe you should look at the CT.
${ }^{1}$ Section of Vascular and Interventional Radiology, University of Chicago Hospitals, Chicago, Illinois.

Address for correspondence and reprint requests: Brian Funaki, M.D., Section of Vascular and Interventional Radiology, University of Chicago Hospitals, 5840 S. Maryland Avenue, MC 2026, Chicago, IL 60637.

Case-Based Interventional Radiology; Guest Editors, Ron C.
Gaba, M.D., Derek L. West, M.D., James T. Bui, M.D., Charles A. Owens, M.D.

Semin Intervent Radiol 2007;24:1-2. Copyright (C) 2007 by Thieme Medical Publishers, Inc., 333 Seventh Avenue, New York, NY 10001, USA. Tel: +1(212) 584-4662.

DOI 10.1055/s-2007-971178. ISSN 0739-9529. 
A
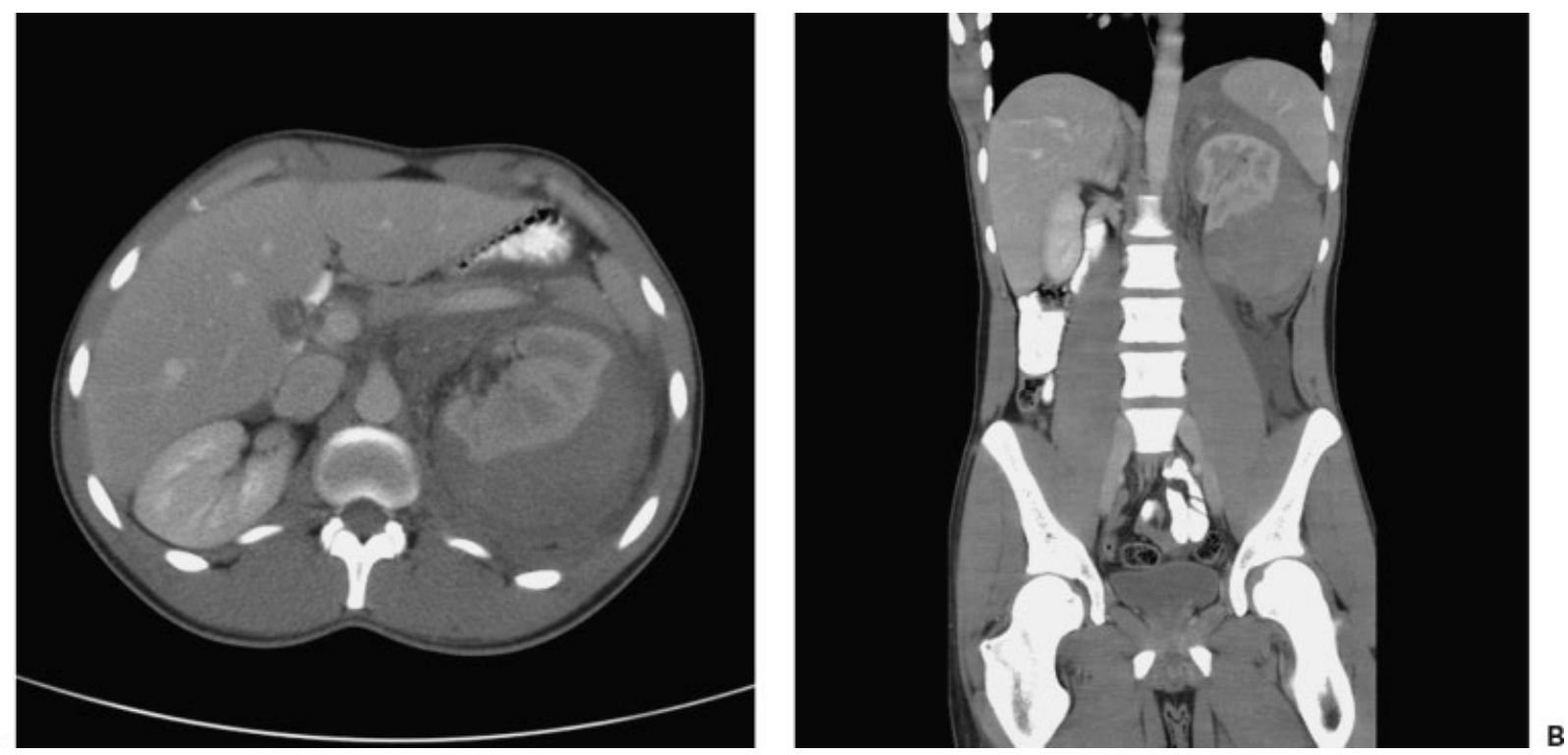

Figure 1 After-hours drainage request. (A) Axial computed tomography (CT) demonstrates large perinephric hematoma. (B) Coronal reformatted CT shows hematomas to better advantage.

Now between you and me, anytime someone wants something done for so-called medicolegal reasons, it usually means there is no medical reason to have it done. Typically someone, somewhere along the line, has screwed up and is worried about being sued. Or the patient is a lawyer.

Fortunately, thanks to the wonders of modern technology, I can nearly instantaneously review any CT at home on my laptop. Ergo, I brought up the relevant study (Fig. 1). Even in a semicomatose state, I can confidently diagnose a perinephric hematoma with the best of diagnostic radiologists. I guess I'm lucky because unlike some of my interventional colleagues who do not routinely interpret CT studies, I do. Maybe my diagnostic colleagues are the ones who are lucky. In any case, my word is the final one on CT interpretations-no conference call is needed at $3 \mathrm{Am}$ to make sure my interpretation is valid.

Three more attempts with intermittent profanity, and I get the 10-digit phone number correct (I always forget about the redial button until I've already screwed up the first time). The radiology resident is now with the urologists.

Me: This is a perinephric hematoma.

Resident: I put that in the differential.

Me: There is no differential-that's what it is.

Resident: They're not convinced.

Me: Honestly, I really don't care. Tell them we're not draining a perinephric hematoma at $3 \mathrm{AM}$ or $3 \mathrm{PM}$. If we do, it really will be "medicolegal." If the patient is hypotensive, we can do an angiogram and embolization; otherwise not. residents.

My resident relayed my interpretation to the

Resident: They said there is no history of trauma, so it is not likely to be a hematoma.

Me: Have they examined the patient yet? Are they aware of other things that can spontaneously bleed, like AMLs for instance?

Resident: AML—good thought.

Me: Thanks, that means a lot to me. Sorry, I'm just tired. If you need me to discuss this with their attending, let me know. We're not draining this.

Honestly, in retrospect, I guess this is a good example of what clearly distinguishes us from surgeons. No matter how well many of them learn minimally invasive procedures, they don't interpret imaging studies as well as a radiologist. As interventional radiologists, we often take our diagnostic ability for granted, but we shouldn't. Among other things, we interpret diagnostic studies better than surgeons, cardiologists, and internists-period. The combination of diagnostic and interventional skills makes us truly unique. This union is among the qualities that make interventional radiologists different and, at times, clearly superior to others in the field of medicine.

\section{Brian Funaki, M.D. ${ }^{1}$} Editor in Chief 